\title{
S-Adenosylmethionine (SAMe) in major depressive disorder (MDD): a clinician-oriented systematic review
}

Alessandro Cuomo ${ }^{1}$, Bruno Beccarini Crescenzi ', Simone Bolognesi , Arianna Goracci', Despoina Koukouna ${ }^{1}$, Rodolfo Rossi ${ }^{2}$ and Andrea Fagiolini ${ }^{*}$ (D)

\begin{abstract}
Background: Major depressive disorder (MDD) is a recurrent illness with high rates of chronicity, treatmentresistance, and significant economic impact. S-Adenosylmethionine (SAMe), a molecule that is formed naturally in the human body, has shown antidepressant effects and may expand the available options for treating MDD. This systematic review examines the evidence concerning the efficacy of SAMe as monotherapy or in combination with antidepressants.
\end{abstract}

Methods: A systematic search in Medline, Psychinfo, AMED, and Cochrane Controlled Trials Register was conducted for any reference recorded up to March 2020. Double-blind, randomised controlled trials, comparing the antidepressant efficacy of SAMe to placebo or/and to other antidepressants, were selected. Two authors evaluated each study independently and then, reconciled findings.

Results: Eight trials, with a total of 11 arms and 1011 subjects, evaluating the efficacy of SAMe used as monotherapy or as adjunctive therapy (512 individuals), were included in this review. The study duration ranged between 2 and 12 weeks and the daily dose of SAMe varied from 200 to $3200 \mathrm{mg}$. Five comparisons evaluated the differences between SAMe and placebo and SAMe resulted significantly better than placebo in three of these studies. Four comparisons evaluated the differences between SAMe and other antidepressants (imipramine or escitalopram) and showed no significant difference. One study showed that SAMe was significantly better than placebo in accelerating the response to imipramine from day 4 to day 12 , but the mean scores were not statistically different at the day 14 endpoint. One study showed that SAMe combined with serotonin reuptake inhibitors (SSRI) was better than PBO combined with SSRI. The studies reported only mild, transient or non-clinically relevant side effects.

Conclusions: The existing trials of SAMe, used as monotherapy or add on to another antidepressants, have shown encouraging and generally positive results. However, more evidence is necessary before definitive conclusions can be drawn. Larger, double-blind randomised controlled studies are warranted to confirm the antidepressant effectiveness of SAMe.

Keywords: Systematic review, S-Adenosylmethionine, Antidepressant, Depression, Nutraceutical

*Correspondence: andreafagiolini@gmail.com

${ }^{1}$ Division of Psychiatry, Department of Molecular Medicine, University of Siena, Siena, Italy

Full list of author information is available at the end of the article

\section{Background}

Major depressive disorder (MDD) is the fourth leading cause of global disease burden [1]. Approximately $40-50 \%$ of patients do not achieve an adequate response after initial treatment $[2,3]$, and full remission is too

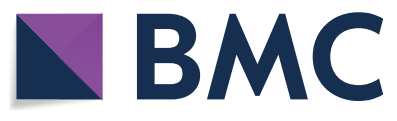

(c) The Author(s) 2020. This article is licensed under a Creative Commons Attribution 4.0 International License, which permits use, sharing, adaptation, distribution and reproduction in any medium or format, as long as you give appropriate credit to the original author(s) and the source, provide a link to the Creative Commons licence, and indicate if changes were made. The images or other third party material in this article are included in the article's Creative Commons licence, unless indicated otherwise in a credit line to the material. If material is not included in the article's Creative Commons licence and your intended use is not permitted by statutory regulation or exceeds the permitted use, you will need to obtain permission directly from the copyright holder. To view a copy of this licence, visit http://creativeco mmons.org/licenses/by/4.0/. The Creative Commons Public Domain Dedication waiver (http://creativecommons.org/publicdomain/ zero/1.0/) applies to the data made available in this article, unless otherwise stated in a credit line to the data. 
often short-lived or absent [4]. Nutraceutical (e.g. omega3, S-adenosylmethionine, or vitamin $\mathrm{D}$ ), used in augmentation or combination with antidepressants, may represent an effective and safe strategy in enhancing antidepressants effects [5-9].

$S$-Adenosylmethionine (SAMe), an endogenous compound that is not readily available from dietary sources $[9,10]$, was discovered in 1952 by the late Italian scientist, Giulio Cantoni [10], marketed since 1999 as a dietary supplement and, then, as an antidepressant [11].

SAMe is a natural sulphur-containing compound with a reactive methyl group [11]. The synthesis of SAMe includes the methylation of homocysteine to methionine by methyltransferase enzyme and cobalamin. Methionine is then converted to SAMe through the enzyme methionine adenosyltransferase. SAMe may play a beneficial role in biochemical mechanisms that have been associated with depression. For instance, SAMe may affect the regulation of a wide range of critical components of neurotransmission [11-17]. SAMe is involved in three central metabolic pathways, namely trans-sulfuration (synthesis of glutathione), transaminopropylation (development of polyamines), and methylation (synthesis of sarcosine; conversion of norepinephrine to epinephrine; catabolism and anabolism of monoaminergic neurotransmitters [11, 12, 16, 17]. Several studies have observed the dysregulation of the one-carbon metabolism, and lower levels of methionine adenosyltransferase enzyme, cerebrospinal fluid SAMe and methylation deficit in patients with MDD [11-14]. Worthy of consideration is also the possibility that SAMe enhances gene expression of brainderived neurotrophic factor $[11,18]$.

SAMe has proved effective in several studies involving patients with MDD [10,11, 21-28]. As for other nutraceuticals, SAMe's optimal dose for depression is still unknown, but oral doses tend to be on average $1600 \mathrm{mg} /$ day, while parental doses range between 200 and $400 \mathrm{mg} /$ day $[20,29]$. To date, oral SAMe dose-response relationship is still unknown although it has been suggested that patients failing to respond to $1600 \mathrm{mg} /$ day may improve after increasing their dose to $3200 \mathrm{mg} /$ day [30]. Tolerability is usually good, but an increased risk of manichypomanic switch has been reported, especially with the parental formulation and for patients with a diagnosis of bipolar disorder [21, 31-35].

A number of studies have investigated the efficacy of SAMe for the treatment of depression and the aim of this paper is to provide an updated overview of the available evidence about the efficacy and tolerability of SAMe, as monotherapy or adjunctive treatment for the treatment of MDD. Our goal is to offer a summary to clinicians interested in prescribing these medications and to identify research gaps or open clinical questions, which may stimulate more studies. Our hypothesis was that the overall results of existing trials were substantially positive, but more research and evidence is needed before the antidepressant effectiveness of SAMe is definitively supported.

\section{Methods}

A systematic search on Medline, Psychinfo, AMED, and Cochrane Controlled Trials Register was conducted on all references published up to March 2020. The search keywords were: SAMe (or $S$-adenosyl methionine or $s$-adenosyl-L-methionine) and major depressive disorder, MDD, depression, and perinatal depression. We included RCTs and considered published and unpublished trials comparing the effectiveness of SAMe versus placebo or active agents, or SAMe combined with other antidepressants in the treatment of MDD. No language or time restrictions were applied. Two authors (AF, AC) screened the results of the search using an over-inclusive approach to construct a list of all potentially relevant articles. The same authors independently screened abstracts, examined the full-text of the most relevant papers. We did not calculate a kappa statistic for measuring the agreement between the two authors because there was not any disagreement. One hundred thirty-two articles were identified, and the cross-check of their references revealed 20 more articles. Fifty-six duplicates were removed from the resulting 152 manuscripts, 40 studies were excluded after reading the abstract (different diagnosis, comparison, intervention, or outcome); subsequently, 26 studies were excluded because they were not original studies or full-text was not available. Finally, 22 more papers were excluded after full-text revision because they included other diagnoses or treatment strategies. Eight doubleblind clinical studies were included in this review (Prisma flowchart-Fig. 1).

\section{Data extraction}

Two authors (AF, AC) independently extracted relevant data from the selected studies. Extracted data were related to one of the following comparisons: SAMe versus placebo as monotherapy, SAMe versus another antidepressant as monotherapy, and SAMe versus placebo as adjunctive treatments to another antidepressant (imipramine or serotonin reuptake inhibitors) (Table 1).

\section{Results}

Eight double-blind randomised and controlled studies were examined. The trials were conducted from 1984 to 2018 and all subjects had a diagnosis of MDD. The number of comparisons was 11, given that three of the eight trials [40-42] included three arms. Two of these trials compared SAMe, escitalopram and placebo [41, 42]. 


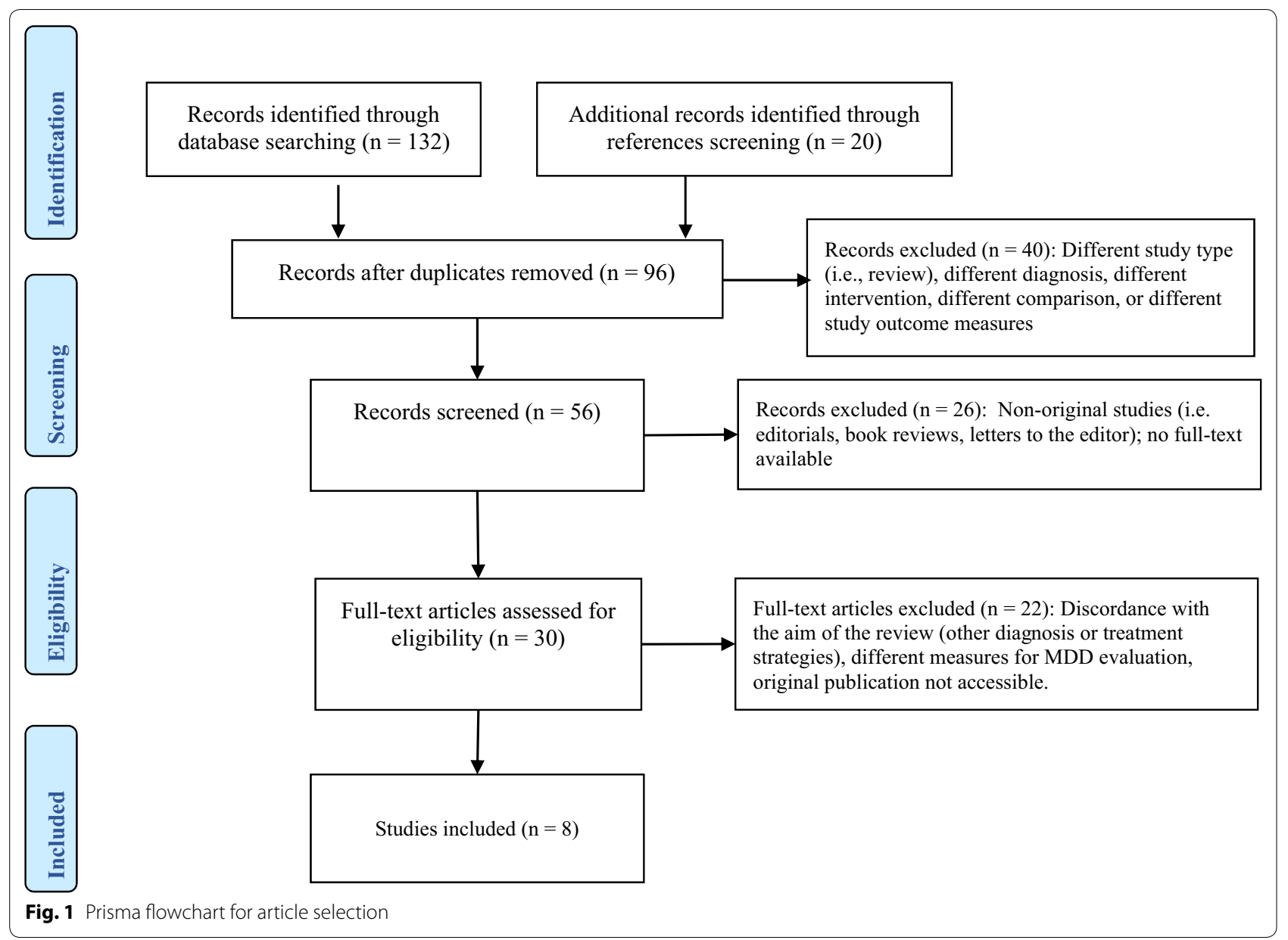

Table 1 Characteristics of the included RCTs of SAMe in MDD

\begin{tabular}{|c|c|c|c|c|c|c|}
\hline Author & Study typology & Duration & Dose SAMe & Administration & Primary outcome & Diagnostic criteria \\
\hline Caruso 1984 [36] & SAMe vs PBO & 3 weeks & $200 \mathrm{mg} /$ day & IM & HAM-D (21 items) & Not specified \\
\hline Kagan 1990 [37] & SAMe vs PBO & 3 weeks & 200 mg/day & OR & HAM-D (21 items) & DSM-III \\
\hline Berlanga 1992 [38] & $\mathrm{SAMe}+\mathrm{IMI}$ vs $\mathrm{PBO}+\mathrm{IMI}$ & 2 weeks & 200 mg/day & IM & HAM-D (17 items) & DSM-III-R \\
\hline Papakostas 2010 [39] & $\mathrm{SAMe}+\mathrm{SRI}$ vS $\mathrm{PBO}+\mathrm{SRI}$ & 6 weeks & $800 \mathrm{mg} /$ day & OR & HAM-D & DSM-IV \\
\hline Delle Chiaie 2002a [40] & SAMe vs IMI & 6 weeks & 1600 mg/day & OR & HAM-D (21 items) & DSM-IV \\
\hline Delle Chiaie 2002b [40] & SAMe vs IMI & 4 weeks & 400 mg/day & IM & HAM-D (21 items) & DSM-IV \\
\hline Mischoulon 2014a [41] & SAMe vs PBO & 12 weeks & 1600-3200 mg/day & OR & HAM-D (17 items) & IDS-C $\geq 25$ \\
\hline Mischoulon 2014b [41] & SAMe vs EST & 12 weeks & 1600-3200 mg/day & OR & HAM-D (17 items) & IDS-C $\geq 25$ \\
\hline Sarris 2014a [42] & SAMe vs PBO & 12 weeks & 1600 mg/day & OR & HAM-D (17 items) & DSM-IV \\
\hline Sarris 2014b [42] & SAMe vs EST & 12 weeks & $1600 \mathrm{mg} /$ day & OR & HAM-D (17 items) & DSM-IV \\
\hline Sarris 2018 [43] & SAMe vs PBO & 8 weeks & 800 mg/day & OR & MADRS & DSM-V \\
\hline
\end{tabular}

$I M$ intramuscular, OR oral, $P B O$ placebo, IMI imipramine, EST escitalopram, MDD major depressive disorder, SAMe S-Adenosylmethionine, SRI serotonin reuptake inhibitors

The remaining study [43] included two multicenter trials, respectively, comparing SAMe oral (first multicenter trial) and SAMe intramuscular (second multicenter trial) to imipramine.
Five comparisons evaluated the differences between SAMe and placebo [36, 37, 41-43]; four comparisons evaluated the differences between SAMe and another antidepressant (imipramine or escitalopram) [40-42]; 
two comparisons evaluated the differences between SAMe and placebo, as adjunctive treatments on top of another antidepressant $[38,39]$.

In 10 of the 11 comparisons, treatment efficacy was determined by the Hamilton Depression Rating Scale (HAM-D). The remaining trial [43] used the Montgomery-Asberg Depression Rating Scale (MADRS) as the primary outcome measure (Table 1). Response to treatment was defined as a reduction of $50 \%$ or more of HAM-D or MADRS.

The mean study duration was $7.3 \pm 4.1$ weeks and the SAMe dose ranged between 200 to $3200 \mathrm{mg} /$ day. Most studies used oral SAMe formulation; three studies tested SAMe intramuscular formulation $[36,38,40]$.

The total number of subjects included in the trials was 1011. Five hundred twelve patients received SAMe alone (468 patients) or combined with imipramine or SRI (44 patients). One hundred sixteen patients received placebo, 20 patients received placebo and imipramine, 31 received placebo and SRI, and 332 received either imipramine or escitalopram (282 imipramine intramuscularly or by mouth, and 50 escitalopram by mouth).

\section{Efficacy}

Table 2 reports a summary of the efficacy and tolerability data in the trials that are reported in this paper.

\section{Comparison 1: SAMe versus placebo as monotherapy}

Five studies compared SAMe and placebo, for a total of 125 patients treated with SAMe as monotherapy and 116 patients treated with placebo. HAM-D score decreased significantly in three out of the five studies [36, 37, 42]. Caruso et al. [36] reported a significant improvement of depression using SAMe at $200 \mathrm{mg} /$ day in intramuscular formulation (SAMe mean difference: 11.4; placebo mean difference: 2.9); Kagan et al. [37] and Sarris et al. [42] reported a significant improvement using SAMe oral formulation at $800 \mathrm{mg} /$ day and $1600 \mathrm{mg} /$ day, respectively.

In a 12-week study [41], patients were randomly assigned to SAMe $1600 \mathrm{mg} /$ day or placebo for the first 6 weeks. From the sixth week, the doses were escalated to maximise the probability of response in the event of noresponse. The authors observed a statistically significant decrease in HAM-D score for the SAMe group until the tenth week of treatment $(p=0.026)$. However, the statistical significance was lost at the study end point (12th week) [41]. Finally, Sarris et al. [43] reported that SAMe was not significantly better than placebo, in a study where SAMe was administered orally at $800 \mathrm{mg} /$ day.

\section{Comparison 2: SAMe versus imipramine and SAMe versus escitalopram as monotherapy}

Four studies compared SAMe monotherapy efficacy with imipramine or escitalopram, with a total number of 343 patients that received SAMe and 332 treated with the other antidepressants. No statistically significant difference emerged [40-42].

\section{Comparison 3: SAMe versus placebo as adjunctive therapy} Two studies [38, 39] analysed SAMe efficacy as adjunctive treatment antidepressant. The trials included a total of 95 subjects (SAMe: 44; placebo: 51). In one of the studies, SAMe resulted significantly better than placebo in accelerating the response to imipramine from fourth to the twelfth day, while the mean HRSD scores no longer differed significantly at day 14 [38]. In the other study, SAMe combined to SSRI was better than SSRI alone in patients with MDD not-responding to SSRIs [39].

\section{Safety and tolerability}

SAMe tolerability was good for most studies. Side effects were only mild and transient. Two studies [39, 43] reported, respectively, two and three withdrawals in the placebo arm, while five and two patients withdrew because of adverse events in the SAMe arm. Typical anticholinergic effects of imipramine (dry mouth, constipation, and tachycardia) and other relatively mild side effects were registered, respectively, in patients treated with IMI [38, 40] or SSRI [39], in monotherapy or in combination with SAMe. For the oral formulation, common mild side effects are gastrointestinal symptoms, sweating, vertigo, dizziness, tachycardia, restlessness, and anxiety $[5,11,20]$. Patients treated with doses higher than $1600 \mathrm{mg} /$ day reported stomach and abdominal discomfort, fluid retention and swelling [30].

\section{Discussion}

Many patients affected by MDD continue to be symptomatic despite second, third, or fourth-line treatment approaches [44] and SAMe may represent a useful aid for the treatment for MDD, especially in those cases where the risk-benefit ratio may not justify the use of less-tolerated pharmacological treatment $[5,10]$. SAMe's mechanism of action is still unclear, but it has been shown that SAMe is able to increase the central turnover rate of dopamine and serotonin [38]. In fact, SAMe raises cerebrospinal fluid levels of both homovanillic acid and 5-hydroxyindoleacetic acid, while lowering the levels of serum prolactin [36]. SAMe is able to impact on the noradrenergic system as well. An increase in the number of beta-adrenergic receptors and in the affinity of alpha1adrenergic receptors for the agonist phenylephrine 
Table 2 Summary of efficacy and tolerability data

\begin{tabular}{|c|c|c|c|c|c|c|c|c|c|}
\hline Study & $\begin{array}{l}\text { SAMe } \\
\text { sample }\end{array}$ & $\begin{array}{l}\text { Control } \\
\text { sample }\end{array}$ & MD SAMe & MD control & Efficacy & Side effects & $\begin{array}{l}\text { Response } \\
\text { method }\end{array}$ & $\begin{array}{l}\text { Response } \\
\text { rate SAMe }\end{array}$ & $\begin{array}{l}\text { Response } \\
\text { rate } \\
\text { control }\end{array}$ \\
\hline $\begin{array}{l}\text { Caruso } 1984 \\
{[36]}\end{array}$ & 25 & 24 & $11.4(7.7)$ & $2.9(6.4)$ & $\begin{array}{l}\text { SAMe better } \\
\text { than pla- } \\
\text { cebo }\end{array}$ & Not reported & NR & NR & $N R$ \\
\hline $\begin{array}{l}\text { Kagan } 1990 \\
{[37]}\end{array}$ & 9 & 6 & $16.2(6.9)$ & $7.3(14.3)$ & $\begin{array}{l}\text { SAMe better } \\
\text { than pla- } \\
\text { cebo }\end{array}$ & $\begin{array}{l}\text { Mild side } \\
\text { effects only, } \\
\text { resolved } \\
\text { spontane- } \\
\text { ously }\end{array}$ & $N R$ & NR & NR \\
\hline $\begin{array}{l}\text { Berlanga } 1992 \\
\quad \text { [38] }\end{array}$ & 20 & 20 & $13.7(4.6)$ & $9.6(6.2)$ & $\begin{array}{l}\text { SAMe + IMI } \\
\text { better } \\
\text { than pla- } \\
\text { cebo + IMI }\end{array}$ & $\begin{array}{l}\text { Typical } \\
\text { anticholin- } \\
\text { ergic effects } \\
\text { of IMI (mild). } \\
\text { Mild weight } \\
\text { gain }\end{array}$ & $\begin{array}{l}\text { Reduction } \\
\mathrm{HAM} \geq 50 \%\end{array}$ & 65 & 45 \\
\hline $\begin{array}{l}\text { Papakostas } \\
2010[39] \text { * }\end{array}$ & 24 & 31 & $11.1(6.1)$ & $15.8(6.2)$ & $\begin{array}{l}\text { SAMe + SRI } \\
\text { better } \\
\text { than pla- } \\
\text { cebo+SRI }\end{array}$ & $\begin{array}{l}\text { Slightly } \\
\text { higher } \\
\text { mean } \\
\text { supine } \\
\text { systolic } \\
\text { blood pres- } \\
\text { sure in the } \\
\text { treatment } \\
\text { group }\end{array}$ & $\begin{array}{l}\text { Reduction } \\
\mathrm{HAM} \geq 50 \%\end{array}$ & 75.0 & 12.9 \\
\hline $\begin{array}{l}\text { Delle Chiaie } \\
\text { 2002a [40] }\end{array}$ & 143 & 135 & $12.6(8.1)$ & $13.1(8.6)$ & $\begin{array}{l}\text { SAMe equal } \\
\text { to imipra- } \\
\text { mine }\end{array}$ & \multirow{2}{*}{$\begin{array}{l}\text { Dry mouth, } \\
\text { constipa- } \\
\text { tion, and } \\
\text { tachycardia. } \\
\text { More fre- } \\
\text { quent IMI }\end{array}$} & $\begin{array}{l}\text { Reduction } \\
\mathrm{HAM} \geq 50 \%\end{array}$ & 51 & 57 \\
\hline $\begin{array}{l}\text { Delle Chiaie } \\
\text { 2002b [40] }\end{array}$ & 146 & 147 & $12.6(8.0)$ & $13.1(7.1)$ & $\begin{array}{l}\text { SAMe equal } \\
\text { to imipra- } \\
\text { mine }\end{array}$ & & $\begin{array}{l}\text { Reduction } \\
\mathrm{HAM} \geq 50 \%\end{array}$ & 58.9 & 50.3 \\
\hline $\begin{array}{l}\text { Mischoulon } \\
\text { 2014a [41] }\end{array}$ & 36 & 31 & $6.19(7.38)$ & $5.11(6.92)$ & $\begin{array}{l}\text { SAMe equal } \\
\text { to placebo }\end{array}$ & \multirow{2}{*}{$\begin{array}{l}\text { Good toler- } \\
\text { ability. Gl } \\
\text { complaints }\end{array}$} & $\begin{array}{l}\text { Reduction } \\
\mathrm{HAM} \geq 50 \%\end{array}$ & 35 & 30 \\
\hline $\begin{array}{l}\text { Mischoulon } \\
\text { 2014b [41] }\end{array}$ & 36 & 30 & $6.19(7.38)$ & $6.31(6.98)$ & $\begin{array}{l}\text { SAMe equal } \\
\text { to escitalo- } \\
\text { pram }\end{array}$ & & $\begin{array}{l}\text { Reduction } \\
\mathrm{HAM} \geq 50 \%\end{array}$ & 35 & 34 \\
\hline $\begin{array}{l}\text { Sarris 2014a } \\
{[42]}\end{array}$ & 18 & 16 & $7.31(5.96)$ & $4.0(5.6)$ & $\begin{array}{l}\text { SAMe better } \\
\text { than pla- } \\
\text { cebo }\end{array}$ & \multirow{2}{*}{$\begin{array}{l}\text { Interventions } \\
\text { were well } \\
\text { tolerated } \\
\text { with no } \\
\text { significant } \\
\text { adverse } \\
\text { effects }\end{array}$} & $\begin{array}{l}\text { Reduction } \\
H A M \geq 50 \%\end{array}$ & 45 & 26 \\
\hline $\begin{array}{l}\text { Sarris 2014b } \\
{[42]}\end{array}$ & 18 & 20 & $7.31(5.96)$ & $6.69(5.7)$ & $\begin{array}{l}\text { SAMe equal } \\
\text { to escitalo- } \\
\text { pram }\end{array}$ & & $\begin{array}{l}\text { Reduction } \\
H A M \geq 50 \%\end{array}$ & 45 & 31 \\
\hline $\begin{array}{l}\text { Sarris } 2018 \\
\text { [43] }\end{array}$ & 37 & 39 & $11.4(7.54)$ & $12.1(7.02)$ & $\begin{array}{l}\text { SAMe equal } \\
\text { to placebo }\end{array}$ & $\begin{array}{l}\text { Irritability, } \\
\text { hot/cold } \\
\text { flashes, } \\
\text { cramping, } \\
\text { confusion, } \\
\text { headache, } \\
\text { vertigo/ } \\
\text { dizziness, } \\
\text { twitching, } \\
\text { sleep dif- } \\
\text { ficulty and } \\
\text { fatigue }\end{array}$ & $\begin{array}{l}\text { Reduction } \\
\quad \text { MADRS } \geq 50 \%\end{array}$ & 54.3 & 50 \\
\hline
\end{tabular}

NR not reported, $M D$ mean difference

has been observed in rats, after the administration of SAMe [45]. Hence, the administration of SAMe leads to modifications in adrenergic neurotransmission that are opposite to those that are classically produced by standard antidepressants: upward regulation of alphaadrenergic receptors and downward regulation of 
beta-adrenergic receptors. Of interest, antidepressant treatments may lead to a depletion of SAMe's concentration in tissues [45], which may be replaced by the administration of more SAMe. Indeed, SAMe's mechanism of action likely involves different neurochemical effects, including enhanced methylation of catecholamines and increased serotonin turnover, reuptake inhibition of norepinephrine, enhanced dopaminergic activity, decreased prolactin secretion, and increased phosphatidylcholine conversion $[19,46]$.

The role of $S$-adenosylmethionine in the treatment of major depressive disorder has been established in clinical studies [5, 20, 35], but some uncertainties remain [34]. Overall, SAMe has demonstrated the ability to induce a valid and effective antidepressants effect, with remarkably few side effects and a relatively rapid onset of action [24]. However, the number of trials that have been conducted to date is relatively small and more trials, involving a greater number of subjects, are needed to definitively establish SAMe effectiveness.

To date, other nutraceuticals, like folic acid, methyl folate, omega-3, and vitamin D, are available and could represent an alternative to SAMe use. However, they are not without risk [47]. For instance, supplements containing folic acid or omega-3 could increase risk of prostate cancer and higher-dose omega- 3 supplementation has been suspected to increase bleeding, impair immune function and metabolism [48-50]. Vitamin D could determine hypercalcemia and vascular calcification if used at high doses ( $\geq 275 \mathrm{mg} /$ day) [35].

\section{Limitations}

Our review has several limitations due to the limited number of studies that have been published and analysed. Furthermore, the SAMe doses that were used in the included trials as well as the observation periods, inclusion criteria, and statistical methods, were not uniform across the studies, making it difficult compare the studies and lump the results together.

\section{Advantages of the revision}

$S$-Adenosylmethionine (SAMe) represents a frequently used antidepressants agent and this revision provides clinicians with a summary of the existing findings and may stimulate researchers to conduct larger trials.

\section{Conclusions}

SAMe, used as monotherapy or combined with other antidepressants, is well tolerated and may improve MDD symptoms. The existing findings are encouraging, but further, well-designed, randomised, controlled clinical trials are needed to provide definitive evidence about
SAMe efficacy and tolerability, both as monotherapy and as adjunctive treatment.

Acknowledgements
The manuscript was supported by an unconditioned Grant from Mylan.

\section{Authors' contributions}

AC and AF have conceptualised and designed the study, selected, and examined the papers that have been reviewed. BBC, SB, AG, DK, RR checked the reference output, the correctness of the outputs and evaluated critically the outcomes. AC drafted the article. AF, BBC, SB, AG, RR and DK revised it critically for important intellectual content. All authors read and approved the final manuscript.

\section{Competing interests}

Andrea Fagiolini is/has been a consultant and/or a speaker and/or has received research grants from Allergan, Angelini, Apsen, Boehringer Ingelheim, Doc Generici, FB-Health, Italfarmaco, Janssen, Lundbeck, Mylan, Otsuka, Pfizer, Recordati, Sanofi Aventis, Sunovion, Vifor. Alessandro Cuomo is/has been a consultant and/or a speaker and/or has received research grants from Angelini, Janssen, Lundbeck, Otsuka, and Pfizer. The other authors declare no conflict of interest.

\section{Author details}

${ }^{1}$ Division of Psychiatry, Department of Molecular Medicine, University of Siena, Siena, Italy. ${ }^{2}$ Department of Systems Medicine, University of Rome tor Vergata, Rome, Italy.

Received: 23 May 2020 Accepted: 27 August 2020

Published online: 05 September 2020

\section{References}

1. World Health Organization. Depression 30', Fact Sheet, 2020. https:// www.who.int/news-room/fact-sheets/detail/depression. Accessed 8 Jan 2020.

2. Fava M. Diagnosis and definition of treatment-resistant depression. Biol Psychiatry. 2003;53(8):649-59. https://doi.org/10.1016/s0006 $-3223(03) 00231-2$

3. Frodl T. Recent advances in predicting responses to antidepressant treatment. F1000Res. 2017;6:F1000. https://doi.org/10.12688/f1000resea rch.10300.1.

4. Shelton RC. What are the comparative benefits and harms of augmentation treatments in major depression? J Clin Psychiatry. 2015;76(4):e531-3. https://doi.org/10.4088/JCP.14com09586.

5. Sarris J, Murphy J, Mischoulon D, et al. Adjunctive nutraceuticals for depression: a systematic review and meta-analyses. Am J Psychiatry. 2016;173(6):575-87. https://doi.org/10.1176/appi.ajp.2016.15091228.

6. Sarris J. Clinical use of nutraceuticals in the adjunctive treatment of depression in mood disorders. Australas Psychiatry. 2017;25(4):369-72. https://doi.org/10.1177/1039856216689533.

7. Schefft C, Kilarski LL, Bschor T, Köhler S. Efficacy of adding nutritional supplements in unipolar depression: a systematic review and metaanalysis. Eur Neuropsychopharmacol. 2017;27(11):1090-109. https://doi. org/10.1016/j.euroneuro.2017.07.004.

8. Wilson A. S-Adenosyl Methionine (SAMe) for Depression in Adults. Issues Ment Health Nurs. 2019;40(8):725-6. https://doi.org/10.1080/01612 840.2017.1392161.

9. Sarris J, Murphy J, Stough C, et al. S-Adenosylmethionine (SAMe) monotherapy for depression: an 8-week double-blind, randomised, controlled trial. Psychopharmacology. 2020;237(1):209-18. https://doi.org/10.1007/ s00213-019-05358-1.

10. Sharma A, Gerbarg P, Bottiglieri T, et al. S-Adenosylmethionine (SAMe) for neuropsychiatric disorders: a clinician-oriented review of research. J Clin Psychiatry. 2017;78(6):e656-67. https://doi.org/10.4088/JCP.16r11113.

11. De Berardis D, Orsolini L, Serroni N, et al. A comprehensive review on the efficacy of S-Adenosyl-L-methionine in major depressive disorder. CNS Neurol Disord: Drug Targets. 2016;15(1):35-44. https://doi. org/10.2174/1871527314666150821103825. 
12. Gao J, Cahill CM, Huang X, et al. S-Adenosyl methionine and transmethylation pathways in neuropsychiatric diseases throughout life. Neurotherapeutics. 2018;15(1):156-75. https://doi.org/10.1007/s13311-017-0593-0.

13. Karas Kuželički N. S-Adenosyl methionine in the therapy of depression and other psychiatric disorders. Drug Dev Res. 2016;77(7):346-56. https:// doi.org/10.1002/ddr.21345.

14. Mischoulon D, Fava M. Role of S-Adenosyl-L-methionine in the treatment of depression: a review of the evidence. Am J Clin Nutr. 2002;76(5):1158S61S. https://doi.org/10.1093/ajcn/76/5.1158S.

15. Bhatia P, Singh N. Homocysteine excess: delineating the possible mechanism of neurotoxicity and depression. Fundam Clin Pharmacol. 2015;29(6):522-8. https://doi.org/10.1111/fcp.12145.

16. Miller AL. The methylation, neurotransmitter, and antioxidant connections between folate and depression. Altern Med Rev. 2008;13(3):216-26.

17. Mato JM, Alvarez L, Ortiz P, Pajares MA. S-Adenosylmethionine synthesis: molecular mechanisms and clinical implications. Pharmacol Ther. 1997;73(3):265-80. https://doi.org/10.1016/s0163-7258(96)00197-0.

18. Ikegame T, Bundo M, Murata Y, Kasai K, Kato T, Iwamoto K. DNA methylation of the BDNF gene and its relevance to psychiatric disorders. J Hum Genet. 2013;58(7):434-8. https://doi.org/10.1038/jhg.2013.65.

19. Papakostas Gl, Alpert JE, Fava M. S-adenosyL-methionine in depression: a comprehensive review of the literature. Curr Psychiatry Rep. 2003;5(6):460-6. https://doi.org/10.1007/s11920-003-0085-2.

20. Galizia I, Oldani L, Macritchie K, et al. S-adenosyl methionine (SAMe) for depression in adults. Cochrane Database Syst Rev. 2016;10(10):CD011286. https://doi.org/10.1002/14651858.cd011286.pub2.

21. Spillmann M, Fava M. S-adenosyL-methionine (ademethionine) in psychiatric disorders. CNS Drugs. 1996;6:416-25.

22. Bressa GM. S-adenosyl-L-methionine (SAMe) as antidepressant: metaanalysis of clinical studies. Acta Neurol Scand Suppl. 1994;154:7-14. https ://doi.org/10.1111/j.1600-0404.1994.tb05403.x.

23. Bell KM, Plon L, Bunney WE Jr, Potkin SG. S-adenosylmethionine treatment of depression: a controlled clinical trial. Am J Psychiatry. 1988;145(9):1110-4. https://doi.org/10.1176/ajp.145.9.1110.

24. Agnoli A, Andreoli V, Casacchia M, Cerbo R. Effect of s-adenosyl-L-methionine (SAMe) upon depressive symptoms. J Psychiatr Res. 1976;13(1):4354. https://doi.org/10.1016/0022-3956(76)90008-x.

25. De Leo D. S-Adenosylmethionine as an antidepressant. A double-blind trial versus placebo. Curr Ther Res Clin Exp. 1987. https://doi.org/10.4088/ JCP.16r11113.

26. Carney MW, Edeh J, Bottiglieri T, Reynolds EM, Toone BK. Affective illness and S-adenosyl methionine: a preliminary report. Clin Neuropharmacol. 1986;9(4):379-85. https://doi.org/10.1097/00002826-198608000-00005.

27. Caruso I, et al. Treatment of depression in rheumatoid arthritic patients. A comparison of S-adenosylmethionine (Samyr*) and placebo in a doubleblind study. Clin. Trials J. 1987. https://doi.org/10.1186/1471-2474-5-6.

28. Miccoli L, Porro V, Bertolino A. Comparison between the antidepressant activity and of S-adenosylmethionine (SAMe) and that of some tricyclic drugs. Acta Neurol (Napoli). 1978;33(3):243-55.

29. Stramentinoli G. Pharmacologic aspects of S-adenosylmethionine. Pharmacokinetics and pharmacodynamics. Am J Med. 1987;83(5A):35-42. https://doi.org/10.1016/0002-9343(87)90849-7.

30. Sakurai H, Carpenter L, Tyrka A, et al. Dose increase of S-AdenosyL-Methionine and escitalopram in a randomized clinical trial for major depressive disorder. J Affect Disord. 2020;262:118-25. https://doi.org/10.1016/j. jad.2019.10.040

31. Carney MW, Martin R, Bottiglieri T, et al. Switch mechanism in affective illness and S-adenosylmethionine. Lancet. 1983;1(8328):820-1. https:// doi.org/10.1016/s0140-6736(83)91876-7.

32. Carney MW, Chary TK, Bottiglieri T, Reynolds EH, Toone BK. Switch mechanism in affective illness and oral S-adenosylmethionine (SAM). Br J Psychiatry. 1987;150:724-5. https://doi.org/10.1192/bjp.150.5.724.

33. Lipinski JF, Cohen BM, Frankenburg F, et al. Open trial of S-adenosylmethionine for treatment of depression. Am J Psychiatry. 1984;141(3):44850. https://doi.org/10.1176/ajp.141.3.448.

34. Mischoulon D, Rapaport MH. Current role of herbal and natural preparations. Handb Exp Pharmacol. 2019;250:225-52. https://doi. org/10.1007/164_2018_152.
35. Sarris J, Byrne GJ, Stough C, et al. Nutraceuticals for major depressive disorder- more is not merrier: an 8-week double-blind, randomised, controlled trial. J Affect Disord. 2019;245:1007-15. https://doi.org/10.1016/j. jad.2018.11.092.

36. Caruso I, Fumagalli M, Boccassini L, Sarzi Puttini P, Ciniselli G, Cavallari G. Antidepressant activity of S-adenosylmethionine. Lancet. 1984;1(8382):904. https://doi.org/10.1016/s0140-6736(84)91360-6.

37. Kagan BL, Sultzer DL, Rosenlicht N, Gerner RH. Oral S-adenosylmethionine in depression: a randomized, double-blind, placebo-controlled trial. Am J Psychiatry. 1990;147(5):591-5. https://doi.org/10.1176/ajp.147.5.591.

38. Berlanga C, Ortega-Soto HA, Ontiveros M, Senties H. Efficacy of S-adenosyl-L-methionine in speeding the onset of action of imipramine. Psychiatry Res. 1992;44(3):257-62. https://doi.org/10.1016/0165-1781(92)90029 $-3$.

39. Papakostas GI, Mischoulon D, Shyu I, Alpert JE, Fava M. S-adenosyl methionine (SAMe) augmentation of serotonin reuptake inhibitors for antidepressant nonresponders with major depressive disorder: a doubleblind, randomized clinical trial. Am J Psychiatry. 2010;167(8):942-8. https ://doi.org/10.1176/appi.ajp.2009.09081198.

40. Delle Chiaie R, Pancheri P, Scapicchio P. Efficacy and tolerability of oral and intramuscular S-adenosyl-L-methionine 1,4-butanedisulfonate (SAMe) in the treatment of major depression: comparison with imipramine in 2 multicenter studies. Am J Clin Nutr. 2002;76(5):1172S-6S. https ://doi.org/10.1093/ajcn/76/5.1172S.

41. Mischoulon D, Price LH, Carpenter LL, et al. A double-blind, randomized, placebo-controlled clinical trial of S-adenosyl-L-methionine (SAMe) versus escitalopram in major depressive disorder. J Clin Psychiatry. 2014;75(4):370-6. https://doi.org/10.4088/JCP.13m08591.

42. Sarris J, Papakostas GI, Vitolo O, Fava M, Mischoulon D. S-adenosyl methionine (SAMe) versus escitalopram and placebo in major depression RCT: efficacy and effects of histamine and carnitine as moderators of response. J Affect Disord. 2014;164:76-81. https://doi.org/10.1016/j. jad.2014.03.041.

43. Sarris J, Byrne GJ, Bousman C, et al. Adjunctive S-adenosylmethionine (SAMe) in treating non-remittent major depressive disorder: an 8-week double-blind, randomized, controlled trial. Eur Neuropsychopharmacol. 2018;28(10):1126-36. https://doi.org/10.1016/j.euroneuro.2018.07.098.

44. Rush AJ, Trivedi MH, Wisniewski SR, et al. Acute and longer-term outcomes in depressed outpatients requiring one or several treatment steps: a STAR*D report. Am J Psychiatry. 2006;163(11):1905-17. https://doi. org/10.1176/ajp.2006.163.11.1905.

45. Cohen BM, Lipinski JF, Vuckovic A, Prosser E. Blood S-adenosyl-L-methionine levels in psychiatric disorders. Am J Psychiatry. 1982;139(2):229-31. https://doi.org/10.1176/ajp.139.2.229.

46. Bottiglieri T, Hyland K. S-adenosylmethionine levels in psychiatric and neurological disorders: a review. Acta Neurol Scand Suppl. 1994;154:1926. https://doi.org/10.1111/j.1600-0404.1994.tb05405.x

47. Marx W, Moseley G, Berk M, Jacka F. Nutritional psychiatry: the present state of the evidence. Proc Nutr Soc. 2017;76(4):427-36. https://doi. org/10.1017/S0029665117002026.

48. Wang R, Zheng Y, Huang JY, Zhang AQ, Zhou YH, Wang JN. Folate intake, serum folate levels, and prostate cancer risk: a meta-analysis of prospective studies. BMC Public Health. 2014;14:1326. https://doi. org/10.1186/1471-2458-14-1326.

49. Fu YQ, Zheng JS, Yang B, Li D. Effect of individual omega-3 fatty acids on the risk of prostate cancer: a systematic review and dose-response metaanalysis of prospective cohort studies. J Epidemiol. 2015;25(4):261-74. https://doi.org/10.2188/jea.JE20140120.

50. Tio M, Andrici J, Cox MR, Eslick GD. Folate intake and the risk of prostate cancer: a systematic review and meta-analysis. Prostate Cancer Prostatic Dis. 2014;17(3):213-9. https://doi.org/10.1038/pcan.2014.16.

\section{Publisher's Note}

Springer Nature remains neutral with regard to jurisdictional claims in published maps and institutional affiliations. 